
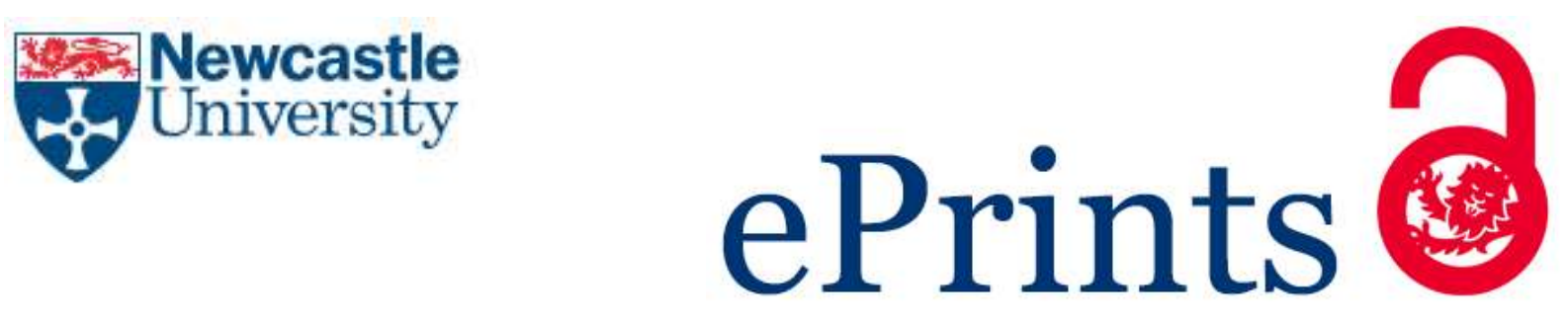

Clowry GJ, Alzu'bi A, Harkin LF, Sarma S, Kerwin J, Lindsay S. Charting the protomap of the human telencephalon. Seminars in Cell and Developmental Biology 2017

\title{
Copyright:
}

(c) 2017. This manuscript version is made available under the CC-BY-NC-ND 4.0 license

DOI link to article:

https://doi.org/10.1016/j.semcdb.2017.08.033

Date deposited:

$06 / 03 / 2018$

Embargo release date:

20 August 2018

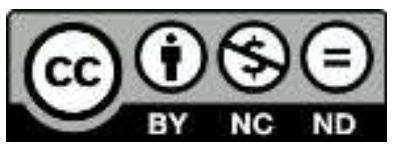

This work is licensed under a

Creative Commons Attribution-NonCommercial-NoDerivatives 4.0 International licence 
Page 1 of 32

\section{Charting the protomap of the human telencephalon}

Gavin J Clowry ${ }^{1^{*}}$, Ayman Alzu'bi $\mathrm{bi}^{1,2}$, Lauren F Harkin ${ }^{3}$, Subrot Sarma ${ }^{4}$, Janet Kerwin ${ }^{2}$, Susan J Lindsay ${ }^{2}$ Institutes of ${ }^{1}$ Neuroscience and ${ }^{2}$ Genetic Medicine, Newcastle University, Newcastle upon Tyne, the United Kingdom.

${ }^{3}$ School of Healthcare Science, Manchester Metropolitan University, the United Kingdom.

${ }^{4}$ Department of Chemistry, Indian Institute of Technology, Mumbai, India.

*author for correspondence, Institute of Neuroscience, Newcastle University, Framlington Place, Newcastle upon Tyne, NE2 4HH, the United Kingdom.

Email address: gavin.clowry@ncl.ac.uk.

Telephone 441912085981

Preprint version

Final version available at doi.org/10.1016/j.semcdb.2017.08.33. 
Page 2 of 32

\section{Abstract}

The cerebral cortex is divided stereotypically into a number of functionally distinct areas. According to the protomap hypothesis formulated by Rakic neural progenitors in the ventricular zone form a mosaic of proliferative units that provide a primordial species-specific cortical map. Positional information of newborn neurons is maintained during their migration to the overlying cortical plate. Much evidence has been found to support this hypothesis from studies of primary cortical areas in mouse models in particular. Differential expansion of cortical areas and the introduction of new functional modules during evolution might be the result of changes in the progenitor cells. The human cerebral cortex shows a wide divergence from the mouse containing a much higher proportion of association cortex and a more complicated regionalised repertoire of neuron sub-types. To what extent does the protomap hypothesis hold true for the primate brain? This review summarises a growing number of studies exploring arealised gene expression in the early developing human telencephalon. The evidence so far is that the human and mouse brain do share fundamental mechanisms of areal specification, however there are subtle differences which could lead us to a better understanding of cortical evolution and the origins of neurodevelopmental diseases.

\section{Keywords:}

Cerebral Cortex, Cortical arealisation, Development, Evolution, Ganglionic Eminences. 
Page 3 of 32

\section{Introduction}

Each individual, excepting those suffering a gross environmental or genetic insult, possesses a telencephalon built in development to the same plan. Different functional modules always appear in the same place, connections between areas are universal and the brain tissue architecture at the cellular level in each module is the same (1) however subtle differences in these parameters may underlie human diversity in intelligence and personality. Furthermore, this basic plan is shared by all mammalian species, for instance the medial ganglionic eminence (MGE) gives rise to certain classes of cortical interneuron, caudal ganglionic eminence (CGE) to others (2). Primary cortical areas occupy the same positions; primary motor cortex is always in the frontal lobe, visual cortex the occipital lobe, etc., however the relative amount of cortex occupied by each primary area can vary dramatically between species (3). Also, in primates and particularly human, there is a more complicated pattern of functional arealisation with a considerably larger proportion devoted to higher functioning association cortex (3-5) .

It is generally accepted that the layout of the cerebral cortex is determined by the co-ordinated and compartmented expression of genes in time and space at the earliest stages of its development, prior to its connection with the sensory input that could drive its maturation (the protomap hypothesis) (6) although spontaneous thalamo-cortical activity may fine tune sensory cortex arealisation before the onset of cortical sensory information processing (7). Certain transcription factors have been identified in rodents (e.g. PAX6, SP8, EMX2, COUP TF1) expressed in gradients across the dorsal telencephalon, their expression controlled by gradients of soluble morphogens such as FGFs, BMPs and SHH released from four discrete forebrain signalling centres; the anterior neural ridge (ANR)/septum, cortical hem, anti-hem/ventral pallium(VP) and thalamic eminence (8-13) . In turn, transcription factors appear to control regional expression of cell adhesion molecules and cell surface receptors (14-17) leading to organization of area specific thalamocortical afferent projections $(18,19)$ gradually turning the protomap into functioning circuitry. Interference in transcription factor expression $(15,20-22)$ or in 
intercellular signalling by applying exogenous morphogens (23-25) leads to expansion or contraction of primary cortical areas. Similarly, the proliferative zones of the ventral telencephalon are divided into distinct regions by expression of transcription factors, which give rise to different functional classes of principally GABAergic neurons $(26,27)$. Again regional identity can be shifted by manipulation of morphogens or transcription factor expression $(28,29)$.

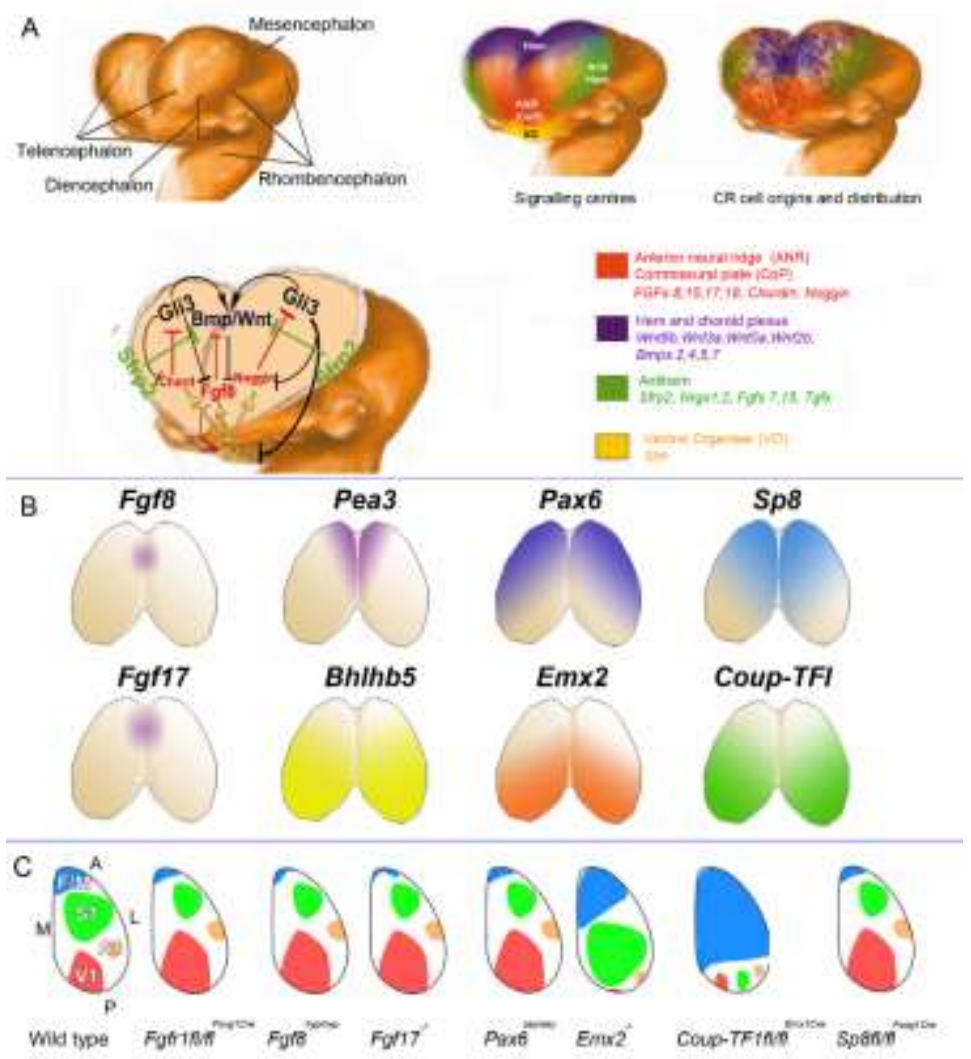

Figure 1 Clowry et al

\section{Figure 1: Generating the protomap in the rodent cortex.}

A. Shows the location of the signalling centres of the forebrain and how CR cells derived from these centres distribute across the cortical surface. It also lists the signalling molecules released from each centre and illustrates how these interact with each other.

B. Shows location of expression of $F g f 8$ and some of its downstream effectors, all of which show high anteromedial expression ( $F g f 17, P e a 3, S p 8)$ along with transcription factors expressed in an opposing gradient (Coup-TFI, Bhblb5) and Pax6 and Emx2, expressed in opposing anterolateral to posteromedial gradients.

C. Summarises the effects of experiments manipulating the expression of these morphogens or transcription factors upon the size and location of primary cortical areas, usually identified and delineated in perinatal animals by expression of specific cell adhesion molecules.

Adapted from (17) . 
Page 5 of 32

The big question, posed by Buckner and Kreinen (5), is whether such a developmental scheme is sufficient to produce all the extra areas of specialised association cortex, along with the vastly increased interconnectivity between these areas, seen in primates? In addition, the degree of specialisation of primate association cortex is not observed in rodents. For instance, the electrophysiological and morphological properties of layer III pyramidal neurones in prefrontal and primary visual cortex are the same in mouse, but not in macaque (30). There is also a greatly increased density of calretinin expressing interneurons in upper layers of association but not primary cortex in humans and monkeys compared to rodents (31). Gene expression studies across the lifespan show that divergent gene expression between cortical regions appears more evident at early fetal stages of development than peri- and post-natally, suggesting that marked inter-areal transcriptional differences are important early in development but replaced by more general differentiation transcriptional programmes later in neural circuit maturation (32). This review examines the evidence for a human protomap and the extent to which it resembles the mouse model, assesses any differences that might explain the evolutionary divergence of human from mouse.

We recently completed the largest RNAseq study to date of human cerebral cortex at its earliest stages of development with 137 samples from different cortical regions with an age range of 7.5 to 17 PCW (33). In the following text, when referring to our own studies, protein coding genes are classified as highly expressed (top 25\%; >40 normalised RPKM) moderate expression (25-50\%: 10-40) low expression (50-75\%; 0.4-10) no expression above background (bottom quartile; $<0.4)(34,35)$. A DESeq analysis (36) of anterior versus posterior gene expression differences in a sub-set of samples from 9 and 12 PCW has also been carried out $(33,34)$.

\subsection{Signalling centres of the human telencephalon}


Page 6 of 32

As described in section 1 , four regions of the mammalian forebrain have been identified as signalling centres releasing soluble morphogens and all have also been identified as a source of Cajal-Retzius (CR) cells with distinct molecular identities depending on their origin (37-39). These early born cells migrate tangentially from the signalling centres across the cortical surface and specific combinations of CR subtypes dynamically populate distinct cortical regions (Fig 1A). Genetic ablation of septum CR cells and redistribution of VP and hem-derived CR subtypes within cortical territories causes changes to early patterning events, and progenitor cell division and differentiation, far removed from CR cell generation sites, correlating with changes in the size and positioning of cortical areas at postnatal stages but without affecting signaling centers (40). As the human cortex is much larger than the rodent such that cortical areas develop further removed from signalling centres, the importance of CR cells as "mobile patterning units" may be increased. Human CR cells have more complex morphologies and developmental programmes than rodent $(41,42)$ and specifically express human accelerated region RNA gene HAR1F (43) suggesting a clear evolutionary trend towards an increased prominence of the cortical hem and hem-derived CR cells destined for the neocortex and hippocampus over other sources (septum, thalamic eminence and amygdalar hem) during human neocortical development (41, 44).

The ANR is the most anterior signalling centre, developing before the septum and is involved in specifying the anterior neural tube around the time of neural tube closure. It, along with the isthmus and zona limitans intrathalamica, have been called secondary organisers because of their roles in establishing major subdivisions of the brain along the anterior-posterior axis (45-48). As in mouse, FGF8 is strongly expressed in the ANR but disappears from here before the beginning of cortical plate formation (49). The septum develops from the ANR and also expresses FGF8 and the related FGFs 17 and 18. Very low expression of FGF8 is detected in human cortical tissue samples from 7.5 PCW onwards, however FGF 17 and 18, whose protein products have similar but not identical 
Page 7 of 32

function to FGF8 (50) are expressed at low to moderate levels but are not relatively up-regulated anteriorly (33).

FGF8 signalling from the ANR/septum leads to appropriate patterning of the ventral telencephalon. Interestingly, production of SHH from the MGE, a key event in this patterning, requires the removal by apoptosis of the FGF8 signalling cells during a specific time window (51). SHH is produced by postmitotic neurons of the human cortex at mid-gestation $(52,53)$ and It has been suggested that SHH signalling can affect human cortical progenitors, leading to the production of limited numbers of interneurons in certain regions of the primate dorsal telencephalon (53).

FGF8 signalling from the septum also delineates the anterior extent of a second medial signalling centre, the cortical hem. In rodents and human, the expression of WNT8B, WNT2B and WNT3A marks the developing cortical hem whereas WNT2B/WNT3A negative and WNT8B positive expression defines the developing hippocampus (Figs. 1A, 2A, B) $(\mathbf{8}, \mathbf{5 4}, \mathbf{5 5})$. WNT signalling from the cortical hem is instrumental in inducing hippocampal formation (56). BMPs and certain WNTs are proposed to be released from the cortical hem and have a dorsalising effect (Fig. 1A) $(10,57)$. BMPs 2,4 and 5 show uniform, low expression anterio-posteriorly in the human cortex between 7.5 and 17 PCW by RNAseq; BMP 7 shows moderate expression but also without arealisation. WNTs $2 B, 3 A, 5 A$ and $8 B$ are all expressed at low levels throughout the cortex (33).

Gene expression studies in chick and mouse initially defined the position of a distinct ventral pallium (VP) anti-hem sector adjacent to the lateral ganglionic eminence along the whole telencephalic rostrocaudal axis $(12,58)$. We reported the existence of an EMX1 negative PAX6 positive human VP at embryonic stages preceding cortical plate formation (59). The VP is also one of several sources of CR cells in the cortical margins (39) and as other sources, (septum, cortical hem and thalamic eminence) are all organiser centres (44) this suggests that the VP/antihem may also function as an organiser. The 
Page 8 of 32

rodent antihem is marked by expression of the secretable WNT antagonist SFRP2 $(9,60)$. We found SFRP2 expression in the VP/anti-hem and thalamic eminence at 7.5 PCW by in situ hybridisation (Fig.

2B) with RNAseq evidence suggesting that high but uniform expression is maintained up to 17.5 PCW.

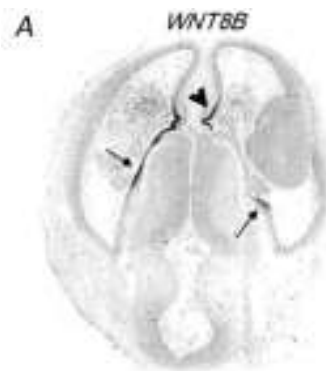

WNTQB
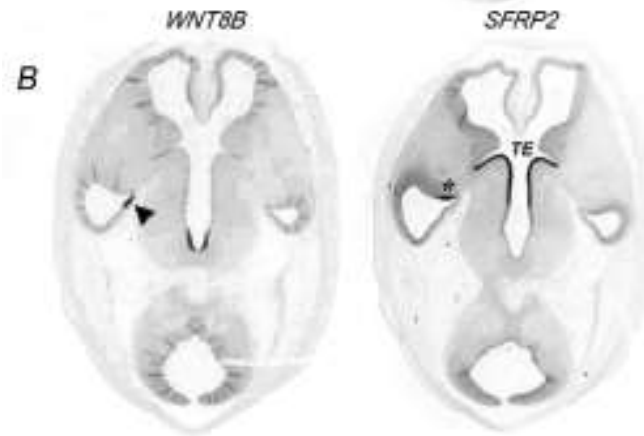

WNT2B
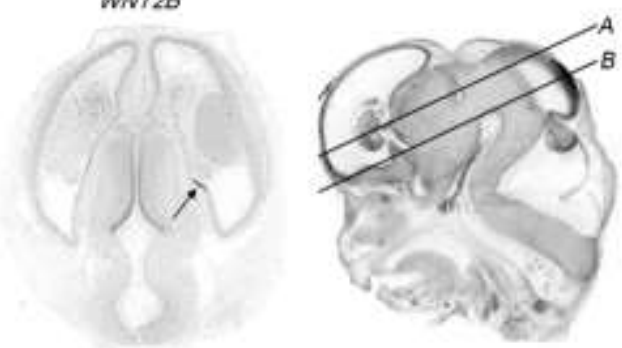

FGFR3

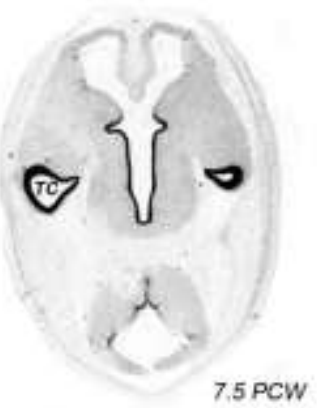

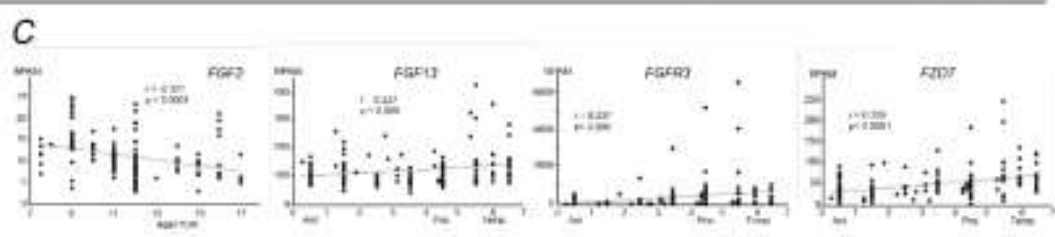

Figure 2 Clowry et al

Figure 2: Signalling centres of the developing human forebrain.

A. Shows more dorsal, and B ventral horizontal sections stained by in situ hybridisation at 7.5 PCW, the very onset of cortical plate formation. WNT8B is expressed throughout both the cortical hem (arrow) and hippocampal primordium (arrowhead) whereas WNT2B is confined to the cortical hem. SFRP2 expression is found in both the anti-hem (asterisk) and thalamic eminence (TE). FGFR3 expression is confined to ventro-posterior areas.

C. An examination of gene expression across the cortex. First FGF2 expression in 137 samples from across the cortex (normalised RPKM) is plotted against age (PCW). There is a significant negative correlation with age. RPKMs for three other genes are plotted against sample location in the cortex; 0 representing the anterior pole, 5 the posterior pole and 7 the temporal pole (after Miller et al, 2014 (52)) . All three show a significant trend towards increased expression in the posterior/temporal cortex. RNA seq data from (33).

2.2 The protomap of the human cerebral cortex 
Page 9 of 32

we would predict that a human protomap would manifest itself in arealised expression firstly of receptors for morphogens, secondly certain transcription factors in the ventricular zone, and thirdly across the cortical wall of transcription factors and other determinants of cell phenotype such as cellcell recognition molecules that determine which synaptic connections these cells ultimately receive and make. Indeed, evidence from published studies $(32,52,61-64)$ supports this prediction to an extent although the restricted amount of information between 7-9 post-conceptional weeks, when the cortical plate just begins to form, is currently a limitation we have tried to address.

\subsubsection{Expression of morphogens and receptors.}

FGFs and FGF receptor expression has been demonstrated in the early human telencephalon $(33,35$, $52,62)$. FGFs have multiple roles in addition to release from signalling centres. Many FGFs showed no expression, but FGF12 and FGF2 are moderately expressed and FGF2 expression decreases with age (Fig. 2C). Fgf2 is expressed in the VZ of mouse cerebral cortex, its protein product playing a role in the expansion of the neural stem cell population (65) therefore it is expected that its expression would decrease with age. FGFs 1, 10 and 16 show upregulation between 9-12 PCW but are hardly expressed above background. FGF 13 shows high expression, particularly in the temporal cortex (Fig. 2C). However FGF13 is one of a family of non-FGF receptor binding FGFs, instead it is a microtubule binding protein with critical roles in cell polarity, cell migration and axon extension (66).

All four FGF receptors are expressed in the early fetal cortex. Both FGFR1 and FGFR2 show moderate to high expression uniformly across the cortex, FGFR4 shows low expression (33). FGFR3 is expressed in a markedly arealised fashion from lowest in the anterior to highest in posterior and temporal cortex along a steep expression gradient (Fig. 2 B,C) $(35,52,62)$ as has been shown in animal models (23). The two different isoforms of FGFR3 interact with overlapping sets of multiple FGF ligands $(67,68)$ but FGF2 could be predicted to have effects upon rates of cell division, acting through one isoform, in the 
Page 10 of 32

posterior and lateral cortex in particular as seen in mouse $(69,70)$ whereas the morphogenetic FGFs $8,17,18$ may act to regulate gene expression through another isoform again acting in posterior and lateral cortex. Interestingly another ligand FGF19, the homologue of mouse Fgf15 which is expressed in the antihem as well as ANR (71) and is an antagonist to FGF 8 (72) appears not to be expressed in the human cerebral cortex at this stage.

As we discussed in section 2.1, expression of BMPS and WNTs remains to be fully characterised in the human cortex. BMP receptor $1 \mathrm{~A}$ is more highly expressed than $1 \mathrm{~B}$ but neither shows arealised expression. WNTs bind multiple Frizzled receptors (FZD)(73) which are all expressed at varying levels. FZD2, 7 and 8 are highly expressed but only FZD7 was found to show a gradient of expression being upregulated in posterior/temporal cortex (Fig. 2C) $(33,74)$.

In conclusion, FGFR3 and FZD7 expression apart, there is little evidence for arealised expression of diffusible morphogens and their receptors in the developing human cerebral cortex post 7.5 PCW, but it may be that the diffusible molecules are largely expressed in tissue not sampled or that these signalling pathways have prominent roles in earlier developmental stages. Next we will consider the expression of downstream arealising transcription factors.

\subsubsection{Transcription factors}

In rodents, the classic example of transcription factors expressed in reciprocal gradients across the cortex is PAX6 and EMX2 which were shown to be present throughout neurogenesis in the proliferative layers; PAX6 high anterolaterally and EMX2 posteromedially. These transcription factors are proposed to impart motor (anterolaterally) and sensory visual (posteromedial) identities by mutually repressing expression of one and other as revealed by gene expression manipulation experiments $(14,20,75)$. This was the first reciprocal gradient also to be revealed in human cortex by in situ hybridisation (Fig. 3A) (76) although only up to 8 PCW after which the PAX6 gradient, at least, 
Page 11 of 32

disappears. Unlike the mouse, EMX2 expression was also seen in post-mitotic neurons of the cortical plate, and it was speculated that EMX2 could interact here with transcription factors expressed downstream of PAX6 such as TBR1 (76). EMX2 expression was also shown to be higher in primary cell cultures from posterior than from anterior cortex at 11 PCW (62) although our recent examination of RNAseq data has failed to show strong evidence of an $E M X 2$ gradient or of a reciprocal expression pattern with PAX6, even at 7.5-9 PCW (Fig. 3D) (33).

However, robust evidence has been found for reciprocal expression of COUP-TFI and SP8 from anteromedial to posterolateral cortex (mRNA and protein Fig 3B, D) (35) as has been observed in rodents (22) With SP8 restricted to VZ except for isolated cells (presumably post-mitotic interneurons)(77) but with COUP-TFI expressed across the cortical wall. Again rodent expression manipulation experiments show these genes have mutually antagonistic effects; loss of COUP-TFI function leads to expansion of frontal motor areas at the expense of posterior sensory areas (21) whereas SP8 loss has the opposite effect (24). COUP-TFI represses FGF signalling by promoting expression of inhibitors sprouty 1 and 2 promoting posterior fate (78) whereas SP8 maintains Fgf8 transcription in the ANR (24).

What was noticeable about expression in humans was that SP8 and COUP-TFI overlap extensively in the VZ of visual, auditory and somatosensory cortex (35). This differs from the mouse in which COUPTFI and SP8 show little overlap (22). Combinatorial expression of COUP-TFI and SP8 could maintain a common genetic identity for future primary sensory areas (visual, auditory and somatosensory) and a partially shared identity with SP8-expressing frontal motor cortex with which these sensory areas will interconnect, along with allied association cortex, via dorsal sensorimotor pathways (79-81). In mouse COUP-TFII is confined to a very small portion of the posterior cortex (82) but in human is expressed extensively throughout the ventral temporal and ventral posterior cortex where it overlaps with COUP-TFI expression (Fig. 3B) (35). Perhaps the expansion of cortical COUP-TFII expressing territory in 
human fetal brain mirrors the increased size and complexity of the association areas of the ventro-

temporal cortex including the ventral stream of cognitive visual processing $(80,83)$.

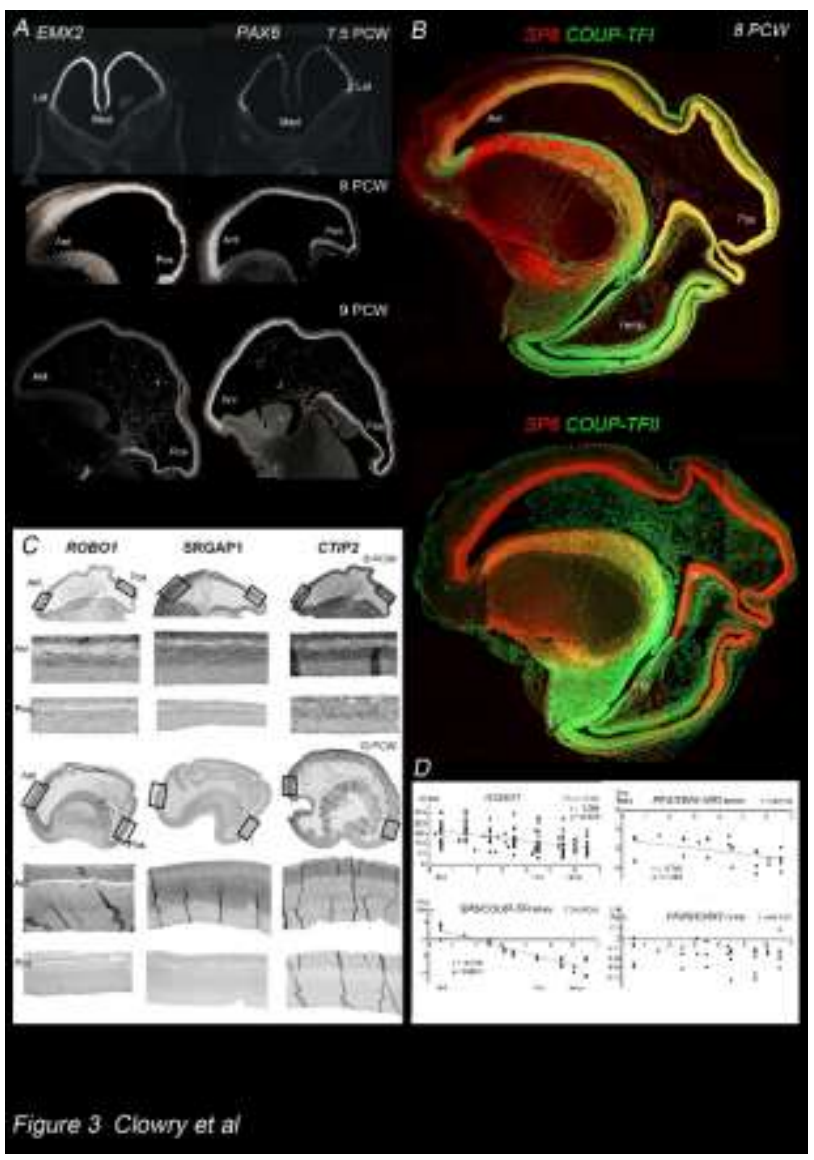

Figure 3. Protomap of the human cerebral cortex

A. Expression of opposing gradients of PAX6 and EMX2 in the human forebrain between 7.5 and 9 post-conceptional weeks (PCW) by in situ hybridisation. Note that the Pax6 gradient disappears by 9 PCW. Adapted from (76). Ant, anterior, Pos, posterior; Med, medial; lat, lateral.

B. Expression of opposing gradients of SP8 with COUP-TFI and COUP-TFII in the human telencephalon by immunofluorescence. Note the extensive overlap of expression of SP8 and COUP-TFI, and the restricted expression of COUP-TFII to the temporal lobe. Adapted from (35).

C. Markers for corticofugal neurons, CTIP2, ROBO1 and SRGAP1 are expressed in a high anterior to low posterior gradient in the human cortex at 8-10 PCW. Adapted from (99)

D. An examination of gene expression from 137 samples across the cortex between ages 7.5-17 PCW (33). Normalised RPKMs for ROBO1 are plotted against sample location in the cortex with 0 representing the anterior pole, 5 the posterior pole and 7 the temporal pole of the cortex (after Miller et al, 2014 (52)). There is a significant trend towards increased expression in the anterior compared to posterior/temporal cortex. To explore coupling of expression between opposing transcription factor gradients we plotted the log of the expression of the putative anterior marker divided by expression of the putative posterior/temporal marker against cortical location. There was a tight correlation between this value and location for SP8/COUP-TFI and PEA3/BHBLB5 but not for PAX6/EMX2.

An extension of this observation is that dorsal (posterior in adult human) and ventral (anterior in adult human) hippocampus are also differentiated by combinatorial expression of SP8/COUP-TFI and COUP- 
Page 13 of 32

TFII/COUP-TFI respectively (Fig 3B) (35). Each domain has distinct functions and distinct efferent and afferent connections (84-86). In mouse that high to low expression of COUP-TFI along a septotemporal gradient is important for the functional organisation of the hippocampus (87). It appears that the protomap for human hippocampal specialisation is laid down early in development and determined by complementary expression of SP8 and COUP-TFII rather than graded expression of COUP-TFI.

Two other transcription factors proposed to be expressed in opposing anteromedial to postero-lateral gradients in mice, PEA3 and BHLHB5 (Fig. 1B) are also expressed in this way in human according to RNAseq evidence (Fig. 3D) (33). In addition to arealised expression across the cortical wall of EMX2, COUP-TFI and COUP-TFII at specific locations, we have also shown that OLIG2 is highly expressed in anteromedially at 7.5-8PCW, although this subsides during development $(88,89)$.

\subsubsection{Cell surface receptors and other phenotypic markers}

Our recent analysis $(33,34,74)$ concurred with previous studies of the whole brain $(64)$ and the cortex at later stages (52) that changes in gene expression with age are more marked than differences between cortical regions. Nevertheless, small subsets of areally expressed genes have been identified in various studies unlike in the adult brain (90). At 9 PCW, the majority of the differentially expressed genes are more highly expressed in anterior than posterior cortex (62) and the genes involved are primarily transcription factors and cell-cell recognition molecules (74). At 12 PCW the pattern shifts and the majority of differentially expressed genes are more highly expressed in the posterior compared to anterior cortex (74) but many of these genes code for proteins involved in neurotransmitter production and synaptic function. In humans, synaptogenesis reaches its peak in visual and auditory cortex within a few months after birth in advance of the prefrontal cortex (91). It seems that this trend begins at a very early stage of development. On the other hand a study at 15-21 PCW again found more anteriorly than posteriorly enriched genes in nearly every layer of the cortical 
Page 14 of 32

wall (52). Furthermore, there was rostral enrichment in genes with considerably accelerated rates of substitution in the human (haCNSs) near conserved non-coding regions, consistent with a developmental role in expansion of the prefrontal cortex in primates, a later developmental event. Surprisingly, nearly a quarter of areally expressed genes in the intermediate zone are haCNSs suggesting this zone is of particular importance in areal cortical identity during human development (52).

Cadherins and related molecules are known to be strongly differentially expressed in cortical areas by late development, for instance Cad6 expression delineates the somatosensory and auditory cortex as well as the thalamic nuclei innervating them (92) however these expression patterns can still be perceived in earlier developing cortex prior to thalamic innervation (93). Differences between patterns of cadherin expression in both postnatal and embryonic cortex differ between marmoset and mouse $(94,95)$ and so it will be important to study the expression of these molecules in human in detail in the future. So far there is some evidence that $\mathrm{CDH7}$ and $\mathrm{PCDH} 8$ are more highly expressed anteriorly $(33,74)$ and stronger evidence that PCDH17 is upregulated anteriorly and delineates the motor cortex by mid-gestation $(33,61,62,74)$. CDH6, CDH9 and PCDH19 may be upregulated posteriorly $(34,74)$.

Members of the Neurexin (NRXN) superfamily have also shown arealised expression. CNTNAP2 (NRXN4) expression has been repeatedly identified as anteriorly upregulated, localising to the prefrontal cortex by mid-gestation $(61-63,96)$. In the mature animal CNTNAP2 organises ion channel localisation at nodes of Ranvier (97) but in development may have roles in cell migration and axon outgrowth (98). NRXN3, although it shows low expression, is upregulated in posterior cortex by 12 PCW $(34,74)$. However CBLN2, a binding partner for neurexins, is upregulated anteriorly at 15-21 PCW (52) although it shows low expression everywhere until after 12 PCW $(34,74)$. 
Page 15 of 32

The identity of cortical regions is determined as much by the identity of the sub-cortical targets they innervate as the thalamo-cortical inputs they receive. For instance in emerging layer $\mathrm{V}$ corticofugal neurons express the transcription factor CTIP2 (99) and cortico-cortical projection neurons express SATB2 (100). We have shown that CTIP2 expression is greater in the frontal cortex between 9-12 PCW (101) which might represent the predominance of corticofugal projection neurons in frontal sensorimotor areas, along with elevated expression of $\operatorname{ROBO}(35,101)$ a transmembrane receptor involved in axon guidance (102) and SRGAP1 (101) its intracellular signal transducer (103) (Fig. 3C). ROBO1 and SRGAP1 expression co-localise with each other and CTIP2 and can be detected in the corticofugal tract at least as far as the medullary decussation at 17 PCW (101). In mouse, COUP-TFI expression in the cortical plate suppresses the differentiation of corticospinal motor neurons in the more caudal somatosensory cortex, allowing for correct specification of these neurons in frontal cortex (104). Our evidence suggests (33) that COUP-TFI expression suppresses CTIP2 expression whereas ROBO1 and SP8 expression are positively correlated.

\subsubsection{Early compartmentalisation of language areas in the human telencephalon}

Language processing may provide the best place to look in the human neocortex for evidence that it is composed of different and more complex local area identities. The use of syntactically complex language to convey abstract information is a unique human attribute mirrored by the existence of multiple language associated areas, asymmetrically distributed between both hemispheres, identified with both the understanding (for instance Wernicke's area in the left parietal cortex) and production (for instance Broca's area in the left frontal cortex) of language (79, 105-107). Profiling gene expression in developing human cerebral cortex has revealed specific features within language areas; for example expression of the transcription factor FOXP2, mutations in which have been implicated in impaired speech development and linguistic deficits $(108,109)$. FOXP2 is shown to be relatively increased in parietal association cortex including Wernicke's area mid-gestation (61) and also participates in human specific regulation of gene expression (110). 
Interestingly, at this stage of development, no asymmetry in gene expression is detected in regions of the perisylvian cortex associated with language $(32,61,63)$ despite the finding of asymmetry in expression of LMO4 and other genes at earlier stages of development (111). However, distinct differences in gene expression are found between areas of developing frontal and parietal cortex (including Broca's and Wernicke's) at mid-gestation (63). Although some transcription factors are amongst these genes, e.g. SOX9 and NURR1 frontally, they mostly comprise genes directly affecting cell phenotype by this stage, e.g. for cell adhesion molecules such as CBLN2, CNTNAP2, CNTN4 frontally and VSTM2L parietally. Again, genes differentially expressed between these regions are enriched in targets for regulation by FOXP2, which shows enrichment in parietal and temporal lobes including presumptive language areas (52) but not genes differentially expressed between 2 age points (17 and 19 PCW) (63).

Other evidence of developmental human specific regulation of gene expression in language areas has been found, for instance, in rapidly evolving microRNAs (43). More recently, Bae et al (112) described a deletion mutation in a regulatory element of GPR56 that causes intellectual disability and epilepsy, and selectively disrupts human cortex surrounding the Sylvian fissure bilaterally including Broca's area. GPR56 encodes a receptor required for normal cortical development that regulates progenitor proliferation. GPR56 splice forms are highly variable between mice and humans, and the disrupted regulatory element directs restricted lateral cortical expression in gyrencephalic mammals only. This study provides a mechanism by which controlling regional GPR56 expression by multiple alternative promoters could influence evolution of cortical arealisation by control of stem cell proliferation and gyral patterning. It has also been found that, exclusively in the human neocortex, the enzyme nitric oxide synthase 1 (NOS1) and the gene expression regulatory protein FMRP are transiently co-expressed during synaptogenesis in subpopulations of pyramidal neurons in regions involved in speech, language, and complex social behaviors. Only in humans and other higher primates is expression of NOS1 regulated by FMRP, where it is co-expressed with FOXP2 (113). 


\subsection{The protomap of the ganglionic eminences}

Combining the findings of a number of studies $(35,77,89,114)$ we can divide the proliferative zones of the human ventral telencephalon according to transcription factor expression (Fig. 4) as has been done in rodent (27) but in human the picture is more complicated. COUP-TFI immunoreactivity subdivides the MGE with NKX2.1 and OLIG2 expressed throughout (Fig. 4 A, B, G) (89) but with COUPTFI confined to the larger dorsal region (Fig. 4 A, B, G)(35). In rodents the dMGE is the birthplace of nearly all parvalbumin-positive $(\mathrm{PV}+)$ and somatostatin-positive $(\mathrm{SST}+)$ cortical interneurons, whereas the vMGE predominantly gives rise to globus pallidus neurons (115). COUP-TFI is co-expressed with SOX6, a downstream regulator of NKX2.1 (116) in the dMGE and in laterally migrating neuroblasts through the LGE and into the cortex (Fig 4 D, G). COUP-TFI may have a role in guiding migration (117) perhaps ensuring migration dorsally towards the cortex and not ventrally towards the basal ganglia.

The confinement of COUP-TFI expression in the VZ to the ventral region also divides the LGE into dorsal and ventral portions. Dorsal LGE (dLGE) is characterised by stronger PAX6 expression, SP8 expression in post-mitotic cells and a few COUP-TFII+ cells (Fig. 4A, E-G). Between 8-12PCW COUP-TFII immunoreactivity in the dLGE appeared to belong only to anteriorly migrating cells arising from the vCGE. Instead, dLGE provided predominantly SP8+ only cells that migrated towards the RMS, amygdala and cortex and did not express CalR. The boundary zone of the MGE and LGE is identified by expression of COUP-TFII (Fig 4B) $(77,89$ ); suggesting it could be an origin for COUP-TFII+ interneurons in addition to the VCGE. In rodents, this boundary region is the source of COUP$\mathrm{TFII+/SOM+} \mathrm{cells} \mathrm{that} \mathrm{occupy} \mathrm{cortical} \mathrm{layer} \mathrm{V} \mathrm{(118).} \mathrm{However,} \mathrm{in} \mathrm{human} \mathrm{there} \mathrm{is} \mathrm{no} \mathrm{co-expression} \mathrm{of}$ COUP-TFII with SOX6 (Figure 4D) the developmental marker for SOM+ interneurons (35) which suggests a difference with mouse where one third of cortical COUP-TFII+ cells co-express SOX6 (119). 


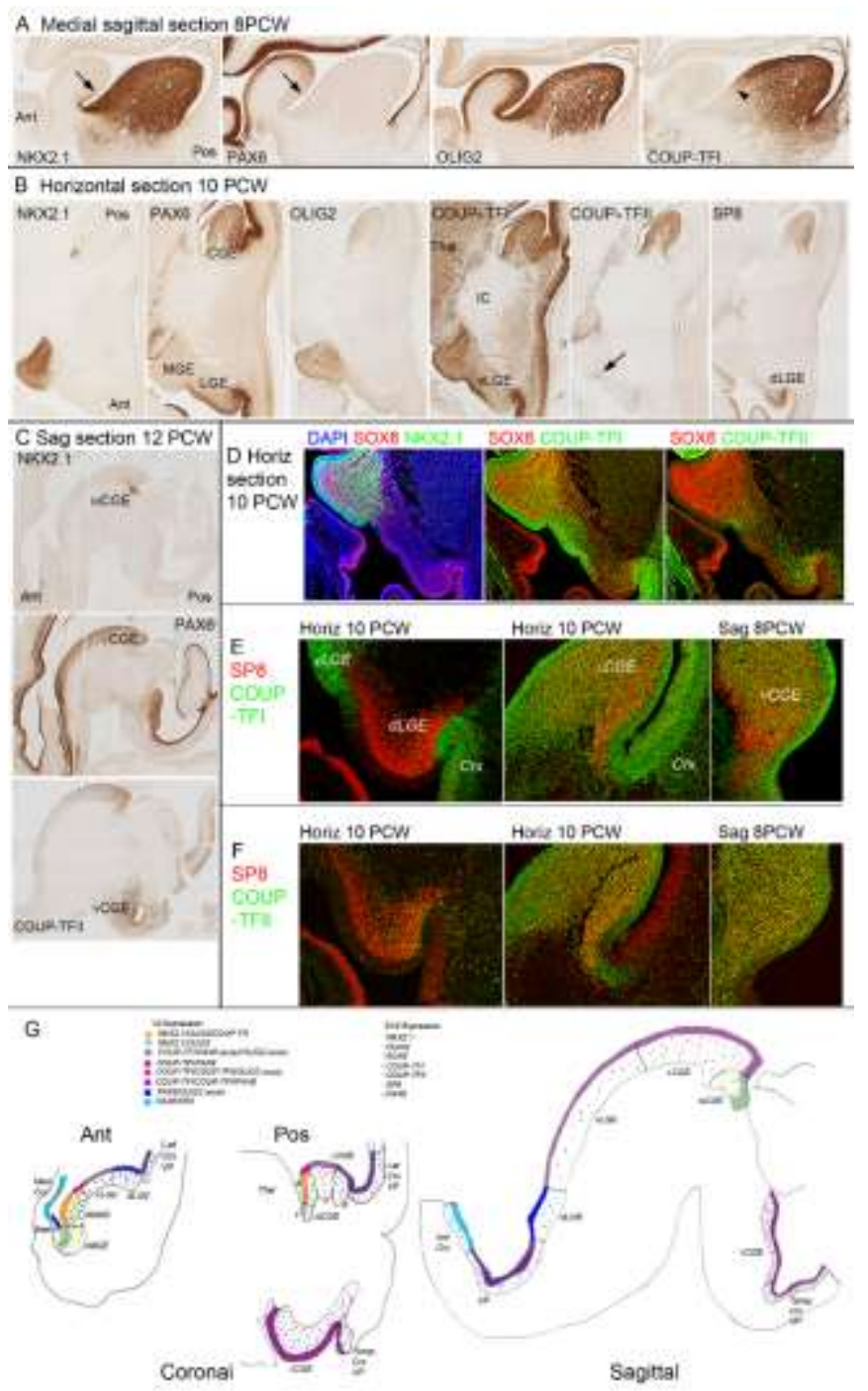

Figure 4 Clowry et al

Figure 4. Compartmentalisation of the developing human ganglionic eminences.

A. Division of the LGE and MGE by transcription factor expression in sagittal sections close to the midline. Arrows show location of the boundary between LGE and MGE. Note the gradient of PAX6 expression across the LGE. The arrowhead shows the boundary between dorsal and ventral MGE. Cortical interneurons of MGE origin very substantially derive from the COUP-TFI positive dorsal MGE.

B. Horizontal sections at a relatively dorsal level show differences between MGE, LGE and dorsal CGE. MGE and MGE-like CGE exclusively express NKX2.1 and OLIG2 whereas COUP-TFI expression extends to LGE-like CGE and ventral LGE. COUP-TFII and SP8 mark the CGE but COUP-TFII also marks the MGE/LGE boundary (arrow) and SP8 is strongly expressed in the dorsal LGE.

C. Further highlights differences between the MGE-like CGE, LGE-like CGE and ventral CGE. Strong PAX6 and COUP-TFII expression in the ventral CGE is continuous with the adjoining ventral temporal cortical wall.

D. Shows that SOX6 expressing interneurons co-express COUP-TFI and derive from the MGE but do not express COUP-TFII.

E. SP8 and COUP-TFI expression sharply delineates the dLGE from the vLGE and cortical ventral pallium (Crx). Relatively small numbers of SP8+/COUPTFI- cells migrate from LGE-like CGE (LCGE) into the cortex at this stage (10 PCW). The ventral CGE (vCGE) SP8+/COUP-TFI+ cells were predominatly observed in the proliferative zones.

F. Low density of COUP-TFII+ cells in SP8+ dLGE but high density of SP8+/COUP-TFII+ cells in the SVZ of the LGE-Like CGE. SP8 highly coexpressed with COUP-TFII in the vCGE.

G. A summary of compartmentalisation of the ganglionic eminences by expression of transcription factors in the proliferative zones (solid colour) and post-mitotic cells (dots).

A-F adapted from $(35,89)$

The sub-cortical septum is divided into MGE-like (NKX2.1 expressing) and LGE-like (PAX6 expressing)

domains with OLIG2+ cells from this compartment migrating medially into the cortex (89). SP8 is 
Page 19 of 32

expressed in LGE-like septum $(35,77)$ and septal SP8+ cells, along with dLGE derived SP8+ cells $(77)$ migrate towards the rostral migratory stream. COUP-TFI and COUP-TFIl expression in both the MGElike and LGE-like septum is confined to a very few, dispersed cells most likely to have migrated from other subcortical structures, making these septal compartments very similar to vMGE and dLGE, respectively (Fig. 4G).

The CGE is characterised by high expression of COUP-TFI and COUP-TFII, as well as SP8 and CalR (Fig 4C, G) $(35,89,114)$. Dorsally, MGE-like CGE expresses NKX2.1, LGE-like CGE expresses PAX6 (89) but neither compartment expresses COUP-TFII in dividing cells of the VZ, which is only seen in the VCGE $(77,89,114)$. COUP-TFII+/CalR cells derived from the vCGE migrate both posteriorly into the temporal cortex and dorsally/laterally/anteriorly via the LGE towards more anterior cortex (89). Many of these cells also express COUP-TFI and SP8 indicating that numerous cells in the LGE co-expressing SP8 and COUP-TFIl are passing through (35) rather than originating from the LGE as previously suggested (77).

\subsubsection{Migration pathways out of the ganglionic eminences delineated by transcription factor} expression.

We would like to propose that regionalised expression of transcription factors in both cortex and the GE controls the migration pathways from ventral to dorsal telencephalon. COUP-TFI is expressed in the ventral pallium along the lateral border of the dorsal telencephalon and in interneuron precursors migrating laterally from either MGE or CGE into the cortex (35). COUP-TFI is proposed to control the lateral/anterior migratory stream of CGE-derived cells in mice (120) in addition to the lateral migration from the MGE to cortex $(121,122)$. In mouse COUP-TFII is important in establishing a caudal migratory stream (CMS) directing CGE-derived cells into temporal cortex and hippocampus (123) (124). In human, COUP-TFII is expressed in temporal and ventral anterior cortex, as well as interneuron precursors generated in the $\operatorname{VCGE}(77,89,114,125)$. Again it appears that COUP-TFII is expressed in gateway regions of the dorsal telencephalon for the entrance of COUP-TFII expressing interneurons 
Page 20 of 32

into the cortex. Similarly, at early developmental stages (8PCW) SP8+ cells migrate from dLGE to SP8+ anterior cortex, but SP8+/COUP-TFII co-expressing cells were not seen within the CMS migrating towards SP8- temporal cortex (35) however this distinction broke down at later developmental stages where SP8+ cells where present in the CMS in abundance.

In addition, we have observed increased expression of OLIG2 in the anterior-medial cortex at 7-8 PCW $(62,88,89)$ in conjunction with a migratory stream of MGE and sub-cortical septum derived OLIG+ cells entering the cortex via the medial wall. This is in direct contradiction to what has been reported in rodents where interneurons populating medial wall derived structures derive from the MGE and CGE via lateral migration $(2,121,126,127)$ with septum-derived cells reported not to enter the cortex at all (128). Thus we propose that the human brain possesses an additional fronto-medial migratory pathway for GABAergic interneurons populating frontal and medial areas of the cerebral cortex. It is worth noting that a medial migratory pathway for Nkx2.1 positive precursors from the MGE to the medial pallium has recently been reported in the shark (129) therefore is not evolutionarily novel to the human brain.

Thus arealised expression of transcription factors in the cortical wall may, in turn, control expression of cell adhesion molecules and chemokine secretion locally that attracts migrating cells expressing the same transcription factors, setting up the migratory pathways into the cortex for interneurons arriving anteriorly or posteriorly, medially or laterally, The much larger human cortex may require additional migratory pathways compared to smaller mammalian brains, although some pathways may not be missing but relatively small and overlooked in rodent.

\section{Conclusions}

Understanding the exact processes by which cortical arealisation and functional regionalisation take place in the human telencephalon are likely to have a huge impact upon both our understanding of 
Page 21 of 32

how the human brain has evolved its higher cognitive functions compared to our model organisms and potentially the sources of neurodevelopmental disease. Early disruption of cortical development can lead to re-specification of regional identity in the cortex with visual cortex developing connectivity characteristic of the motor cortex, for instance (130). Schizophrenic and autistic spectrum disorders may involve more subtle and localised disruptions of regional identity $(131,132)$ that lead to failure of the correct formation of cortico-cortical and cortico-thalamic connectivity. We hope this review has revealed the extent of the progress made so far, and highlighted both the strengths and limitations of our mouse models in unravelling these complex events.

\section{Acknowledgements}

Human embryonic and fetal tissues used in our work and other studies cited in this review were provided by the MRC/Wellcome Trust funded (grant \# 099175/Z/12/Z) Human Developmental Biology Resource (www.hdbr.org;(133)). Other research carried out by the authors has principally been funded by the Wellcome Trust, the Medical Research Council and the Anatomical Society. Ayman Alzu'bi is in receipt of a studentship from Yarmouk University, Jordan. We are grateful to the many colleagues who have collaborated with us in this endeavour but in particular to the staff of the Human Developmental Biology Resource, Dr Nadhim Bayatti and Dr Bui Kar Ip.

\section{References}

1. Rakic P. Evolution of the neocortex: a perspective from developmental biology. Nature Reviews Neuroscience. 2009;10(10):724-35. 
2. Wonders CP, Anderson SA. The origin and specification of cortical interneurons. Nature Reviews Neuroscience. 2006;7(9):687-96.

3. Krubitzer LA, Seelke AMH. Cortical evolution in mammals: the bane and beauty of phenotypic variability. Proceedings of the National Academy of Sciences. 2012;109(Supplement 1):10647-54.

4. Van Essen DC, Dierker DL. Surface-based and probabilistic atlases of primate cerebral cortex. Neuron. 2007;56(2):209-25.

5. Buckner RL, Krienen FM. The evolution of distributed association networks in the human brain. Trends in Cognitive Sciences. 2013;17(12):648-65.

6. Rakic P. Specification of cerebral cortical areas. Science. 1988;241(4862):170.

7. Moreno-Juan V, Filipchuk A, Antón-Bolanos N, Mezzera C, Gezelius H, Andrés B, et al. Prenatal thalamic waves regulate cortical area size prior to sensory processing. Nature Communications. 2017;8.

8. Grove EA, Tole S, Limon J, Yip L-w, Ragsdale CW. The hem of the embryonic cerebral cortex is defined by the expression of multiple Wnt genes and is compromised in Gli3-deficient mice. Development. 1998;125(12):2315-25.

9. Assimacopoulos S, Grove EA, Ragsdale CW. Identification of a Pax6-dependent epidermal growth factor family signaling source at the lateral edge of the embryonic cerebral cortex. Journal of Neuroscience. 2003;23(16):6399-403.

10. Shimogori T, Banuchi V, Ng HY, Strauss JB, Grove EA. Embryonic signaling centers expressing BMP, WNT and FGF proteins interact to pattern the cerebral cortex. Development. 2004;131(22):5639-47.

11. Storm EE, Garel S, Borello U, Hebert JM, Martinez S, McConnell SK, et al. Dosedependent functions of Fgf8 in regulating telencephalic patterning centers. Development. 2006;133(9):1831-44.

12. Medina L, Legaz I, González G, De Castro F, Rubenstein JLR, Puelles L. Expression of Dbx1, Neurogenin 2, Semaphorin 5A, Cadherin 8, and Emx1 distinguish ventral and lateral pallial histogenetic divisions in the developing mouse claustroamygdaloid complex. Journal of Comparative Neurology. 2004;474(4):504-23.

13. Mangale VS, Hirokawa KE, Satyaki PRV, Gokulchandran N, Chikbire S, Subramanian L, et al. Lhx2 selector activity specifies cortical identity and suppresses hippocampal organizer fate. Science. 2008;319(5861):304-9. 
14. Muzio L, Di Benedetto B, Stoykova A, Boncinelli E, Gruss P, Mallamaci A. Emx2 and Pax6 control regionalization of the pre-neuronogenic cortical primordium. Cerebral cortex. 2002;12(2):129-39.

15. O'Leary DDM, Chou S-J, Sahara S. Area patterning of the mammalian cortex. Neuron. 2007;56(2):252-69.

16. Rakic P, Ayoub AE, Breunig JJ, Dominguez MH. Decision by division: making cortical maps. Trends in neurosciences. 2009;32(5):291-301.

17. Alfano C, Studer M. Neocortical arealization: evolution, mechanisms, and open questions. Developmental neurobiology. 2013;73(6):411-47.

18. López-Bendito G, Molnár Z. Thalamocortical development: how are we going to get there? Nature Reviews Neuroscience. 2003;4(4):276-89.

19. Zembrzycki A, Chou S-J, Ashery-Padan R, Stoykova A, O'Leary DDM. Sensory cortex limits cortical maps and drives top-down plasticity in thalamocortical circuits. Nature neuroscience. 2013;16(8):1060-7.

20. Bishop KM, Goudreau G, O'Leary DDM. Regulation of area identity in the mammalian neocortex by Emx2 and Pax6. Science. 2000;288(5464):344-9.

21. Armentano M, Chou S-J, Tomassy GS, Leingärtner A, O'Leary DDM, Studer M. COUP-TFI regulates the balance of cortical patterning between frontal/motor and sensory areas. Nature neuroscience. 2007;10(10):1277-86.

22. Borello U, Madhavan M, Vilinsky I, Faedo A, Pierani A, Rubenstein J, et al. Sp8 and COUP-TF1 reciprocally regulate patterning and Fgf signaling in cortical progenitors. Cerebral Cortex. 2013:bhs412.

23. Fukuchi-Shimogori T, Grove EA. Emx2 patterns the neocortex by regulating FGF positional signaling. Nature neuroscience. $2003 ; 6(8): 825-31$.

24. Sahara S, Kawakami Y, Belmonte JCI, O'Leary DDM. Sp8 exhibits reciprocal induction with Fgf8 but has an opposing effect on anterior-posterior cortical area patterning. Neural development. 2007;2(1):10.

25. Fukuchi-Shimogori T, Grove EA. Neocortex patterning by the secreted signaling molecule FGF8. Science. 2001;294(5544):1071-4.

26. Xu Q, Cobos I, De La Cruz E, Rubenstein JL, Anderson SA. Origins of cortical interneuron subtypes. The Journal of neuroscience. 2004;24(11):2612-22. 
27.Flames N, Pla R, Gelman DM, Rubenstein JLR, Puelles L, Marín O. Delineation of multiple subpallial progenitor domains by the combinatorial expression of transcriptional codes. The Journal of Neuroscience. 2007;27(36):9682-95.

28. Lodato S, Tomassy GS, De Leonibus E, Uzcategui YG, Andolfi G, Armentano M, et al. Loss of COUP-TFI alters the balance between caudal ganglionic eminence-and medial ganglionic eminence-derived cortical interneurons and results in resistance to epilepsy. The Journal of Neuroscience. 2011;31(12):4650-62.

29. Gutin G, Fernandes M, Palazzolo L, Paek H, Yu K, Ornitz DM, et al. FGF signalling generates ventral telencephalic cells independently of SHH. Development. 2006;133(15):2937-46.

30. Gilman JP, Medalla M, Luebke JI. Area-specific features of pyramidal neurons-a comparative study in mouse and rhesus monkey. Cerebral Cortex. 2016:bhw062.

31. Džaja D, Hladnik A, Bičanić I, Baković M, Petanjek Z. Neocortical calretinin neurons in primates: increase in proportion and microcircuitry structure. Frontiers in neuroanatomy. 2014;8.

32. Pletikos M, Sousa AMM, Sedmak G, Meyer KA, Zhu Y, Cheng F, et al. Temporal specification and bilaterality of human neocortical topographic gene expression. Neuron. 2014;81(2):321-32.

33. Lindsay SJ, Xu Y, Lisgo SN, Harkin LF, Copp AJ, Gerrelli D, et al. HDBR Expression: A unique resource for global and individual gene expression studies during early human brain development. Frontiers in neuroanatomy. 2016;10.

34. Harkin LF, Lindsay SJ, Xu Y, Alzu'bi A, Ferrara A, Gullon EA, et al. Neurexins 1-3 Each Have a Distinct Pattern of Expression in the Early Developing Human Cerebral Cortex. Cerebral Cortex. 2017;27:216-32.

35. Alzu'bi A, Lindsay SJ, Harkin LF, McIntyre J, Lisgo SN, Clowry GJ. The transcription factors COUP-TFI and COUP-TFII have 1 distinct roles in arealisation and GABAergic interneuron specification in the early human fetal telencephalon. Cerebral Cortex. 2017;27: 4677-4690.

36. Anders $S$, Huber W. Differential expression analysis for sequence count data. Genome biology. 2010;11(10):R106.

37. Meyer G, Perez-Garcia CG, Abraham H, Caput D. Expression of p73 and Reelin in the developing human cortex. Journal of Neuroscience. 2002;22(12):4973-86.

38. Hanashima C, Fernandes M, Hebert JM, Fishell G. The role of Foxg1 and dorsal midline signaling in the generation of Cajal-Retzius subtypes. Journal of Neuroscience. 2007;27(41):11103-11.

39. Bielle F, Griveau A, Narboux-Nême N, Vigneau S, Sigrist M, Arber S, et al. Multiple origins of Cajal-Retzius cells at the borders of the developing pallium. Nature neuroscience. $2005 ; 8(8): 1002-12$. 
40. Griveau A, Borello U, Causeret F, Tissir F, Boggetto N, Karaz S, et al. A novel role for Dbx1-derived Cajal-Retzius cells in early regionalization of the cerebral cortical neuroepithelium. PLoS Biol. 2010;8(7):e1000440.

41.Meyer G. Building a human cortex: the evolutionary differentiation of Cajal-Retzius cells and the cortical hem. Journal of anatomy. 2010;217(4):334-43.

42. Meyer G, Goffinet AM. Prenatal development of reelin-immunoreactive neurons in the human neocortex. Journal of Comparative Neurology. 1998;397(1):29-40.

43. Pollard KS, Salama SR, Lambert N, Lambot M-A, Coppens S, Pedersen JS, et al. An RNA gene expressed during cortical development evolved rapidly in humans. Nature. 2006;443(7108):167-72.

44. Roy A, Gonzalez-Gomez M, Pierani A, Meyer G, Tole S. Lhx2 regulates the development of the forebrain hem system. Cerebral cortex. 2013:bhs421.

45. Shimamura K, Rubenstein JL. Inductive interactions direct early regionalization of the mouse forebrain. Development. 1997;124(14):2709-18.

46. Vieira C, Garda A-L, Shimamura K, Martinez S. Thalamic development induced by Shh in the chick embryo. Developmental biology. 2005;284(2):351-63.

47. Kiecker C, Lumsden A. Hedgehog signaling from the ZLI regulates diencephalic regional identity. Nature neuroscience. 2004;7(11):1242-9.

48. Martinez-Ferre A, Martinez S. Molecular regionalization of the diencephalon. Frontiers in neuroscience. 2012;6:73.

49. HuDSeN. http://vinovia.ncl.ac.uk/emagewebapp/pages/eadhb_home.jsf.

50. Cholfin JA, Rubenstein JLR. Frontal cortex subdivision patterning is coordinately regulated by Fgf8, Fgf17, and Emx2. Journal of Comparative Neurology. 2008;509(2):144-55.

51. Nonomura K, Yamaguchi Y, Hamachi M, Koike M, Uchiyama Y, Nakazato K, et al. Local apoptosis modulates early mammalian brain development through the elimination of morphogen-producing cells. Developmental cell. 2013;27(6):621-34.

52. Miller JA, Ding S-L, Sunkin SM, Smith KA, Ng L, Szafer A, et al. Transcriptional landscape of the prenatal human brain. Nature. 2014;508(7495):199-206.

53. Radonjić NV, Memi F, Ortega JA, Glidden N, Zhan H, Zecevic N. The role of sonic hedgehog in the specification of human cortical progenitors in vitro. Cerebral Cortex. 2016;26(1):131-43.

54. Lako M, Lindsay S, Bullen P, Wilson DI, Robson SC, Strachan T. A novel mammalian wnt gene, WNT8B, shows brain-restricted expression in early development, with sharply 
delimited expression boundaries in the developing forebrain. Human molecular genetics. 1998;7(5):813-22.

55. Abu-Khalil A, Fu L, Grove EA, Zecevic N, Geschwind DH. Wnt genes define distinct boundaries in the developing human brain: implications for human forebrain patterning. Journal of Comparative Neurology. 2004;474(2):276-88.

56. Subramanian L, Tole S. Mechanisms underlying the specification, positional regulation, and function of the cortical hem. Cerebral Cortex. 2009;19(suppl 1):i90-i5.

57. Sur M, Rubenstein JLR. Patterning and plasticity of the cerebral cortex. Science. 2005;310(5749):805-10.

58. Puelles L, Kuwana E, Puelles E, Bulfone A, Shimamura K, Keleher J, et al. Pallial and subpallial derivatives in the embryonic chick and mouse telencephalon, traced by the expression of the genes Dlx-2, Emx-1, Nkx-2.1, Pax-6, and Tbr-1. Journal of Comparative Neurology. 2000;424(3):409-38.

59. Lindsay S, Sarma S, Martinez-De-La-Torre M, Kerwin J, Scott M, Ferran JL, et al. Anatomical and gene expression mapping of the ventral pallium in a three-dimensional model of developing human brain. Neuroscience. 2005;136(3):625-32.

60. Kawano Y, Kypta R. Secreted antagonists of the Wnt signalling pathway. Journal of cell science. $2003 ; 116(13): 2627-34$.

61. Johnson MB, Kawasawa YI, Mason CE, Krsnik Ž, Coppola G, Bogdanović D, et al. Functional and evolutionary insights into human brain development through global transcriptome analysis. Neuron. 2009;62(4):494-509.

62. Ip BK, Wappler I, Peters H, Lindsay S, Clowry GJ, Bayatti N. Investigating gradients of gene expression involved in early human cortical development. Journal of anatomy. 2010;217(4):300-11.

63. Lambert N, Lambot M-A, Bilheu A, Albert V, Englert Y, Libert F, et al. Genes expressed in specific areas of the human fetal cerebral cortex display distinct patterns of evolution. PloS one. 2011;6(3):e17753.

64. Kang HJ, Kawasawa YI, Cheng F, Zhu Y, Xu X, Li M, et al. Spatio-temporal transcriptome of the human brain. Nature. 2011;478(7370):483-9.

65. Vaccarino FM, Schwartz ML, Raballo R, Nilsen J, Rhee J, Zhou M, et al. Changes in cerebral cortex size are governed by fibroblast growth factor during embryogenesis. Nature neuroscience. 1999;2(3):246-53.

66. Wu Q-F, Yang L, Li S, Wang Q, Yuan X-B, Gao X, et al. Fibroblast growth factor 13 is a microtubule-stabilizing protein regulating neuronal polarization and migration. Cell. 2012;149(7):1549-64. 
67. Ornitz DM, Xu J, Colvin JS, McEwen DG, MacArthur CA, Coulier F, et al. Receptor specificity of the fibroblast growth factor family. Journal of Biological Chemistry. 1996;271(25):15292-7.

68. Mason I. Initiation to end point: the multiple roles of fibroblast growth factors in neural development. Nature Reviews Neuroscience. 2007;8(8):583-96.

69. Iwata T, Hevner RF. Fibroblast growth factor signaling in development of the cerebral cortex. Development, growth \& differentiation. 2009;51(3):299-323.

70. Moldrich RX, Mezzera C, Holmes WM, Goda S, Brookfield SJ, Rankin AJ, et al. Fgfr3 regulates development of the caudal telencephalon. Developmental Dynamics. 2011;240(6):1586-99.

71. Gimeno L, Brulet P, Martí S. Study of Fgf15 gene expression in developing mouse brain. Gene expression patterns. 2003;3(4):473-81.

72. Borello U, Cobos I, Long JE, Murre C, Rubenstein JLR. FGF15 promotes neurogenesis and opposes FGF8 function during neocortical development. Neural development. 2008;3(1):17.

73. Huang H-C, Klein PS. The Frizzled family: receptors for multiple signal transduction pathways. Genome biology. 2004;5(7):234.

74. Harkin LF. The expression of autism susceptibility genes in the earliest stages of human cerebral cortex development. PhD Thesis, Newcastle University. 2017.

75. Bishop KM, Rubenstein JLR, O'Leary DDM. Distinct Actions of Emx1, Emx2, andPax6 in Regulating the Specification of Areas in the Developing Neocortex. Journal of Neuroscience. $2002 ; 22(17): 7627-38$.

76. Bayatti N, Sarma S, Shaw C, Eyre JA, Vouyiouklis DA, Lindsay S, et al. Progressive loss of PAX6, TBR2, NEUROD and TBR1 mRNA gradients correlates with translocation of EMX2 to the cortical plate during human cortical development. European Journal of Neuroscience. 2008;28(8):1449-56.

77. Ma T, Wang C, Wang L, Zhou X, Tian M, Zhang Q, et al. Subcortical origins of human and monkey neocortical interneurons. Nature neuroscience. 2013;16(11):1588-97.

78. Faedo A, Borello U, Rubenstein JLR. Repression of Fgf signaling by sprouty1-2 regulates cortical patterning in two distinct regions and times. Journal of Neuroscience. 2010;30(11):4015-23.

79. Hickok G, Poeppel D. The cortical organization of speech processing. Nature Reviews Neuroscience. 2007;8(5):393-402.

80. Milner AD, Goodale MA. Two visual systems re-viewed. Neuropsychologia. 2008;46(3):774-85. 
81. Baker SN. Oscillatory interactions between sensorimotor cortex and the periphery. Current opinion in neurobiology. 2007;17(6):649-55.

82. Qiu Y, Cooney AJ, Kuratani S, DeMayo FJ, Tsai SY, Tsai M-J. Spatiotemporal expression patterns of chicken ovalbumin upstream promoter-transcription factors in the developing mouse central nervous system: evidence for a role in segmental patterning of the diencephalon. Proceedings of the National Academy of Sciences. 1994;91(10):4451-5.

83. Kaas JH. The evolution of brains from early mammals to humans. Wiley Interdisciplinary Reviews: Cognitive Science. 2013;4(1):33-45.

84. Fanselow MS, Dong H-W. Are the dorsal and ventral hippocampus functionally distinct structures? Neuron. 2010;65(1):7-19.

85. Aggleton JP, Wright NF, Vann SD, Saunders RC. Medial temporal lobe projections to the retrosplenial cortex of the macaque monkey. Hippocampus. 2012;22(9):1883-900.

86. Strange BA, Witter MP, Lein ES, Moser EI. Functional organization of the hippocampal longitudinal axis. Nature Reviews Neuroscience. 2014;15(10):655-69.

87. Flore G, Di Ruberto G, Parisot J, Sannino S, Russo F, Illingworth EA, et al. Gradient COUP-TFI expression is required for functional organization of the hippocampal septotemporal longitudinal axis. Cerebral Cortex. 2016:bhv336.

88. Al-Jaberi N, Lindsay S, Sarma S, Bayatti N, Clowry GJ. The early fetal development of human neocortical GABAergic interneurons. Cereb Cortex. 2015 Mar;25(3):631-45. PubMed PMID: 24047602. Pubmed Central PMCID: 4318531.

89. Alzu'bi A, Lindsay S, Kerwin J, Looi SJ, Khalil F, Clowry GJ. Distinct cortical and sub-cortical neurogenic domains for GABAergic interneuron precursor transcription factors NKX2. 1, OLIG2 and COUP-TFII in early fetal human telencephalon. Brain Structure and Function. 2016:1-20.

90. Roth RB, Hevezi P, Lee J, Willhite D, Lechner SM, Foster AC, et al. Gene expression analyses reveal molecular relationships among 20 regions of the human CNS. neurogenetics. 2006;7(2):67-80.

91. Huttenlocher PR, Dabholkar AS. Regional differences in synaptogenesis in human cerebral cortex. Journal of comparative Neurology. 1997;387(2):167-78.

92. Terakawa YW, Inoue YU, Asami J, Hoshino M, Inoue T. A sharp cadherin-6 gene expression boundary in the developing mouse cortical plate demarcates the future functional areal border. Cerebral Cortex. 2013;23(10):2293-308.

93. Nakagawa Y, Johnson JE, O'Leary DDM. Graded and areal expression patterns of regulatory genes and cadherins in embryonic neocortex independent of thalamocortical input. Journal of Neuroscience. 1999;19(24):10877-85. 
94. Matsunaga E, Nambu S, Oka M, Iriki A. Differential cadherin expression in the developing postnatal telencephalon of a new world monkey. Journal of Comparative Neurology. 2013;521(17):4027-60.

95. Matsunaga E, Nambu S, Oka M, Iriki A. Complex and dynamic expression of cadherins in the embryonic marmoset cerebral cortex. Development, growth \& differentiation. 2015;57(6):474-83.

96. Abrahams BS, Tentler D, Perederiy JV, Oldham MC, Coppola G, Geschwind DH. Genome-wide analyses of human perisylvian cerebral cortical patterning. Proceedings of the National Academy of Sciences. 2007;104(45):17849-54.

97. Poliak S, Gollan L, Martinez R, Custer A, Einheber S, Salzer JL, et al. Caspr2, a new member of the neurexin superfamily, is localized at the juxtaparanodes of myelinated axons and associates with $\mathrm{K}+$ channels. Neuron. 1999;24(4):1037-47.

98. Peñagarikano O, Abrahams BS, Herman EI, Winden KD, Gdalyahu A, Dong H, et al. Absence of CNTNAP2 leads to epilepsy, neuronal migration abnormalities, and core autism-related deficits. Cell. 2011;147(1):235-46.

99. Arlotta P, Molyneaux BJ, Chen J, Inoue J, Kominami R, Macklis JD. Neuronal subtype-specific genes that control corticospinal motor neuron development in vivo. Neuron. 2005;45(2):207-21.

100. Alcamo EA, Chirivella L, Dautzenberg M, Dobreva G, Fariñas I, Grosschedl R, et al. Satb2 regulates callosal projection neuron identity in the developing cerebral cortex. Neuron. 2008;57(3):364-77.

101. Ip BK, Bayatti N, Howard NJ, Lindsay S, Clowry GJ. The corticofugal neuronassociated genes ROBO1, SRGAP1, and CTIP2 exhibit an anterior to posterior gradient of expression in early fetal human neocortex development. Cerebral Cortex. 2011;21(6):1395-407.

102. López-Bendito G, Flames N, Ma L, Fouquet C, Di Meglio T, Chedotal A, et al. Robo1 and Robo2 cooperate to control the guidance of major axonal tracts in the mammalian forebrain. Journal of Neuroscience. 2007;27(13):3395-407.

103. Wong K, Ren X-R, Huang Y-Z, Xie Y, Liu G, Saito H, et al. Signal transduction in neuronal migration: roles of GTPase activating proteins and the small GTPase Cdc42 in the Slit-Robo pathway. Cell. 2001;107(2):209-21.

104. Tomassy GS, De Leonibus E, Jabaudon D, Lodato S, Alfano C, Mele A, et al. Areaspecific temporal control of corticospinal motor neuron differentiation by COUP-TFI. Proceedings of the National Academy of Sciences. 2010;107(8):3576-81.

105. Vigneau M, Beaucousin V, Hervé P-Y, Jobard G, Petit L, Crivello F, et al. What is right-hemisphere contribution to phonological, lexico-semantic, and sentence processing?: Insights from a meta-analysis. Neuroimage. 2011;54(1):577-93. 
106. Glasser MF, Rilling JK. DTI tractography of the human brain's language pathways. Cerebral cortex. 2008;18(11):2471-82.

107. Friederici AD. The brain basis of language processing: from structure to function. Physiological reviews. 2011;91(4):1357-92.

108. Fisher SE, Scharff C. FOXP2 as a molecular window into speech and language. Trends in Genetics. 2009;25(4):166-77.

109. MacDermot KD, Bonora E, Sykes N, Coupe A-M, Lai CSL, Vernes SC, et al. Identification of FOXP2 truncation as a novel cause of developmental speech and language deficits. The American Journal of Human Genetics. 2005;76(6):1074-80.

110. Konopka G, Bomar JM, Winden K, Coppola G, Jonsson ZO, Gao F, et al. Humanspecific transcriptional regulation of CNS development genes by FOXP2. Nature. 2009;462(7270):213-7.

111. Sun T, Patoine C, Abu-Khalil A, Visvader J, Sum E, Cherry TJ, et al. Early asymmetry of gene transcription in embryonic human left and right cerebral cortex. Science. 2005;308(5729):1794-8.

112. Bae B-I, Tietjen I, Atabay KD, Evrony GD, Johnson MB, Asare E, et al. Evolutionarily dynamic alternative splicing of GPR56 regulates regional cerebral cortical patterning. Science. 2014;343(6172):764-8.

113. Kwan KY, Lam MMS, Johnson MB, Dube U, Shim S, Rašin M-R, et al. Speciesdependent posttranscriptional regulation of NOS1 by FMRP in the developing cerebral cortex. Cell. 2012;149(4):899-911.

114. Hansen DV, Lui JH, Flandin P, Yoshikawa K, Rubenstein JL, Alvarez-Buylla A, et al. Non-epithelial stem cells and cortical interneuron production in the human ganglionic eminences. Nat Neurosci. 2013 11//print;16(11):1576-87.

115. Flandin P, Kimura S, Rubenstein JLR. The progenitor zone of the ventral medial ganglionic eminence requires $\mathrm{Nkx2-1}$ to generate most of the globus pallidus but few neocortical interneurons. Journal of Neuroscience. 2010;30(8):2812-23.

116. Batista-Brito R, Rossignol E, Hjerling-Leffler J, Denaxa M, Wegner M, Lefebvre V, et al. The cell-intrinsic requirement of Sox6 for cortical interneuron development. Neuron. 2009;63(4):466-81.

117. Boudot A, Kerdivel G, Lecomte S, Flouriot G, Desille M, Godey F, et al. COUP-TFI modifies CXCL12 and CXCR4 expression by activating EGF signaling and stimulates breast cancer cell migration. BMC cancer. 2014;14(1):407.

118. Cai Y, Zhang Q, Wang C, Zhang Y, Ma T, Zhou X, et al. Nuclear receptor COUPTFII-expressing neocortical interneurons are derived from the medial and lateral/caudal ganglionic eminence and define specific subsets of mature interneurons. Journal of Comparative Neurology. 2013;521(2):479-97. 
119. Ma T, Zhang Q, Cai Y, You Y, Rubenstein JLR, Yang Z. A subpopulation of dorsal lateral/caudal ganglionic eminence-derived neocortical interneurons expresses the transcription factor Sp8. Cerebral Cortex. 2012;22(9):2120-30.

120. Touzot A, Ruiz-Reig N, Vitalis T, Studer M. Molecular control of two novel migratory paths for CGE-derived interneurons in the developing mouse brain. Development. 2016;143(10):1753-65.

121. Faux C, Rakic S, Andrews W, Britto JM. Neurons on the move: migration and lamination of cortical interneurons. Neurosignals. 2012;20(3):168-89.

122. Marín O. Cellular and molecular mechanisms controlling the migration of neocortical interneurons. European Journal of Neuroscience. 2013;38(1):2019-29.

123. Yozu M, Tabata H, Nakajima K. The caudal migratory stream: a novel migratory stream of interneurons derived from the caudal ganglionic eminence in the developing mouse forebrain. The Journal of neuroscience. 2005;25(31):7268-77.

124. Kanatani S, Yozu M, Tabata H, Nakajima K. COUP-TFII is preferentially expressed in the caudal ganglionic eminence and is involved in the caudal migratory stream. The Journal of neuroscience. 2008;28(50):13582-91.

125. Reinchisi G, Ijichi K, Glidden N, Jakovcevski I, Zecevic N. COUP-TFII expressing interneurons in human fetal forebrain. Cerebral Cortex. 2012;22(12):2820-30.

126. Pleasure SJ, Anderson S, Hevner R, Bagri A, Marin O, Lowenstein DH, et al. Cell migration from the ganglionic eminences is required for the development of hippocampal GABAergic interneurons. Neuron. 2000;28(3):727-40.

127. Morozov YM, Torii M, Rakic P. Origin, early commitment, migratory routes, and destination of cannabinoid type 1 receptor-containing interneurons. Cerebral Cortex. 2009:bhp028.

128. Rubin AN, Alfonsi F, Humphreys MP, Choi CKP, Rocha SF, Kessaris N. The germinal zones of the basal ganglia but not the septum generate GABAergic interneurons for the cortex. Journal of Neuroscience. 2010;30(36):12050-62.

129. Quintana-Urzainqui I, Rodríguez-Moldes I, Mazan S, Candal E. Tangential migratory pathways of subpallial origin in the embryonic telencephalon of sharks: evolutionary implications. Brain Structure and Function. 2015;220(5):2905-26.

130. Basu A, Graziadio S, Smith M, Clowry GJ, Cioni G, Eyre JA. Developmental plasticity connects visual cortex to motoneurons after stroke. Annals of neurology. 2010;67(1):132-6.

131. Catani M, Dell'Acqua F, Budisavljevic S, Howells H, de Schotten MT, FroudistWalsh $\mathrm{S}$, et al. Frontal networks in adults with autism spectrum disorder. Brain. 2016;139(2):616-30. 
Page 32 of 32

132. Dorph-Petersen K-A, Lewis DA. Postmortem structural studies of the thalamus in schizophrenia. Schizophrenia research. 2017;180:28-35.

133. Gerrelli D, Lisgo S, Copp AJ, Lindsay S. Enabling research with human embryonic and fetal tissue resources. Development. 2015;142(18):3073-6. 